\title{
Monitoring Temperature Bayi Dengan Sistem Wireless Sensor Network Berbasis Arduino Uno ATmega328
}

\author{
Ahmad Taqwa $^{1}$, Sholihin ${ }^{2}$, dan Elpin Romansyah ${ }^{3}$ \\ 1,2,3 Jurusan Teknik Elektro, Program Studi Teknik Telekomunikasi, Politeknik Negeri Sriwijaya \\ Jl. Srijaya Negara, Bukit Besar, Kec. Ilir Barat I, Kota Palembang, Sumatera Selatan, 30139 \\ Email: alvinromansyah28@gmail.com
}

\begin{abstract}
Abstrak - Pentingnya pengawasan suhu terhadap bayi premature yang harus dirawat secara intesnsif pada tabung inkubator, yang saat ini masih menggunakan cara yang manual sehingga mengakibatkan perawat yang bertugas harus mengecek keadaan suhu inkubator setiap saat berakibat perawat kelelahan. Maka dari itu pada penelitian ini merancang sebuah alat yang dapat memonitoring temeprature secara otomatis dengan sistem wireless sensor network yang di koneksikan dengan jaringan internet agar dapat di monitoring dengan jarak jauh, yang berupa web, jika temperature pada tabung tidak sesuai maka lampu akan redup atau mati sehingga kipas akan menyala secara otomatis untuk mengembalikan temperature dalam keadaan normal. Keadaan suhu normal berada pada range $\left\langle 32^{\circ} \mathrm{C}\right.$ dan suhu diatas $>32^{\circ}$ lampu secara otomatis akan redup atau mati sehingga kipas menyala untuk membantu menormalkan suhu pada tabung inkubator agar kembali stabil.
\end{abstract}

Kata kunci: Arduino Uno, dht11, Inkubator, Monitoring, Wireless Sensor Network.

\begin{abstract}
Abstack - The importance of temperature control for premature babies who must be treated intesively in incubator tubes, which currently still uses manual mrthods so that nurses in charge must check the temperature of the incubator at any time resulting in nurses fatigye. Therefore in this study designed a device that can monitor temperature automatically with a wireless sensor network system that is connected to the internet so that it can be monitored remotely, in the form of the web, if the tube is not appropriate then the lights will be dim or turn off so the fan will turn on automatically to restore the temperature under normal. The normal temperature is in the range $<32^{\circ} \mathrm{C}$ and the temperature above $>32^{\circ} \mathrm{C}$ the lamp will automatically dim or turn off so that the fan turns on to help normalize the temperature in the incubator tube so that it does not overheat and return stable.
\end{abstract}

\section{PENDAHULUAN}

Dizaman yang modern ini teknologi sangat maju dibuktikan dengan banyaknya penemuan-penemuan yang yang dapat mempermudah pekerjaan manusia. Dengan adanya teknologi banyak sekali industri yang terbantu bukan hanya saja rumah tangga.

Terkhusus pada industri kesehatan, dalam dunia kesehatan inkubator ialah salah satu alat yang sangat penting untuk perawatan bayi premature, bayi premature merupakan bayi berumur dalam kandungan kurang dari 37 minggu yang mengharuskan suhu bayi tersebut harus stabil dikarekan bayi tersebut belum terbiasa dengan lingkungan diluar kandungan sang ibu. Inkubator ini yang berfungsi untuk menjaga agar temperature pada bayi terus dalam keadaan stabil. Sistem yang masih digunakan pada inkubator rumah sakit kebanyakan masih manual yaitu onoff control

Pada saat ini sering kali terjadi kecelakaan pada bayi di tabung inkubator, yang mengakibatkan bayi mengalami kepanasan hingga bayi meninggal dunia[1]. kejadian ini diakibatkan oleh beberapa hal, mulai dari sistem kendali temperature pada tabung tidak beroperasi dengan baik, serta kurangnya pengawasan petugas yang jarak ruang inkubator dan perawat berjauhan sehingga tidak termonitoring secara teratur. inkubator bayi memiliki beberapa parameter yaitu temeperature, kelembaban, air flow dan noise. Dengan tingkat kelayakan kebocoran suhu luar $\pm 1^{\circ} \mathrm{C}$, tingkat kelembaban antara $>-70 \%$, laju aliran udara $<0,35 \mathrm{~ms}$, dan tingkat kebisingan di dalam inkubator $<60$ dBA. Persyaratan tersebut harus dipenuhi untuk mendaptkan kreteria keselamatan dan keamanan dalam penggunaanya [2].

Setiap bayi dalam inkubator wajib dilakukan perawatan khusus serta pemantauan pada setiap waktu, akan tetapi sering terjadi kelalaian dalam pemantauan bayi yang berada di tabung inkubator sehingga keadaan lingkungan pada bayi tidak terminitoring dengan baik sehingga berakibat kegagalan pada fungsi inkubator bayi. Keadaan seperti ini dapat merepotkan perawat yang bertugas pada ruangan inkubator, untuk itu agar dapat dengan mudah melakukan monitoring temperature pada inkubator bayi memerlukan sebuah sistem yang dapat dimonitorig dengan jarak jauh, sehingga perawat tidak perlu setiap saat melakukan pengecekkann temperature secara berkala cukup dengan memantau mengunakan handphone atau komputer yang sudah di koneksikan dengan internet menggunakan sistem wireless sensor network. 


\section{STUDI PUSTAKA}

\section{Inkubator Bayi}

Inkubator bayi adalah salah satu alat medis yang digunakan untuk menjaga suhu sebuah tabung supaya suhu tetap stabil. Inkubator bayi merupakan salah satu metode dan sarana yang berfungsi untuk menunjang kedaan bayi yang baru lahir. Terutama pada bayi yang terlahir prematur.

\section{Wireless Sensor Network}

Wireless Sensor Network (WSN) adalah sebuah jaringan nirkabel yang terdiri dari banyak sensor node yang secara acak ataupun manual diletakkan pada sebuah area target. WSN adalah suatu alat sistem embedded yang berkomunikasi tanpa kabel yang di dalamnya terdapat satu atau lebih sensor dan di lengkapi dengan peralatan sistem komunikasi. Dalam penggunaanya ada tiga jenis topologi yaitu topologi star, cluster tree, dan mesh. Dalam pemilihan topologi ini bertujuan menyesuaikan dengan kebutuhan dan medan penempatan [3].

\section{Internet Of Things}

Internet of Things atau dikenal juga dengan singkatan IoT merupakan sebuah konsep yang bertujuan untuk memperluas manfaat dan konektivitas internet yang tersambung secara terus menerus. Adapun kemampuan seperti berbagi data, remote control dan sebagainya termasuk pada semua tersambung kejaringan lokal ataupun global melalui sensor yang tertanam dan selalu aktif [4].

\section{Arduino Uno}

Arduino uno adalah salah satu jenis rangkaian mikrokontroller ATmega328. Board ini memiliki 14 pin digital input output \{dimana 6 pin dapat digunakan sebagai output PWM), 6 input analog, $16 \mathrm{MHz}$ osilator kristal, koneksi USB, konektor listrik, tombol reset. Pin-pin ini berisi semua yang diperlukan mikrokontroller, hanya terhubung ke komputer dengan kabel USB atau sumber tegangan bisa didapat dari adaptor AC-DC atau baterai untuk menggunakannya [5].

\section{ATMEGA 328}

Ini adalah otak papan pada arduino, komponen ini ialah sebuah IC (Integreted Circuit). yang di pasang ke header socket sehingga memunginkan untuk dilepas. Chip ATmega328 memiliki banyak fasilitas, chip tersebut memiliki 23 jalur general purpose I/O (input/output), 32 buah register, 3 buah timer/counter dengan mode perbandingan . interupt internal dan external, serial programmable USART, 2- wire interface serial port SPI, 6 buah channel 10-bit A/D converter, programmable watchdog timer dengan oscilator internal, dan lima power saving mode [6].

\section{Sensor DHT11}

DHT11 merupakan sebuah sensor suhu dan kelebaban . yang memiliki keluaran sinyal digital dan dapat dikalibrasi sengan sensor suhu dan kelembaban. Stabilitas yang baik merupakan salh satu sifat sensor ini, sensor dht11 memiliki respons yang cepat, memiliki keakuratan yang tinggi dalam kalibrasi, serta harga yang murah.
Sensor ini menggunakan dua buah probe untuk melewati arus dan kemudian membaca resistansi untuk mendapatkan tingkat kelembaban udara. Prinsip kerjanya ialah memberikan nilai keluaran berupa besaran listrik sebagai adanya air yang berada dilempeng kapasitor sensor tersebut [7]

\section{Push Button}

Push button switch (saklar tombol tekan) merupakan perangkat/saklar sederhana yang berfungsi untuk menghubungkan atau memutuskan aliran arus listrik dengan sistem kerja unlock disini saklar bekerja sebagai device atau penghubung atau pemutus aliran arus listrik saat tombol ditekan, dan saat tombol tidak ditekan (dilepas), maka saklar akan kembali ke kondisi normal.

\section{Relay}

Relay adalah saklar (switch) yang di operasikan secara listrik dan merupakan komponen Electromechanical yang terdiri dari 2 bagian utama yaitu Elektromagnet (Coil) dan mekanikal (Seperangkat kontak saklar/switch). realay mengunakan prinsip elektromagnetik untuk menggerakkan kontak saklar sehingga dengan arus listrik yang kecil (low power) dapat menghantarkan listrik bertegangan lebih tinggi [6].

Empat dasar komponen relay, yaitu :

1) Elektromagnet (Coil)
2) Armature
3) Switch Contact Point (Saklar)
4) Spring

\section{Modul GSM SIM 800L}

SIM8001 adalah salah satu module GSM/GPRS serial yang dapat digunakan bersma arduino/AVR ada beberapa tipe dari breakout board SIM800/SIM800L. Modul SIMM800L memiliki dimensi yang kecil sehingga lebih cocok untuk diaplikasikan pada perancangan alat yang didesain portable. SIM800L memiliki Quad Band 850/900/1800/1900 MHz dengan dimensi kecil yaitu ukuran 15.8 x 17.8 x $2.4 \mathrm{~mm}$ dan berat 1:35g. SIM800L memiliki konsumsi daya yang rendah dengan rentang tegangan power supplay $3.4 \sim 4.4 \mathrm{v}[8]$.

\section{Liquid Crystal Display (LCD)}

LCD (Liquid Crystal Display) adalah suatu jenis modul tampilan elektronik berukuran 16x2 yang memiliki fungsi sebagai tampilan suatu data, baik karakter, huruf ataupun grafik. LCD sangat berfungsi sebagai penampil yang nantinya akan digunakan sebagai penampil data keluaran dari sensor suhu. Material LCD adalah lapisan dari campuran organik antara lapisan kaca bening dengan elektroda pada kaca belakang. LCD sangat berfungsi sebagai penampil yang nantinya akan digunakan untuk menampilkan status kerja alat [9]. Adapun fitur-fitur yang ada pada LCD ialah :
a) Terdiri dari 16 karakter dari 2 baris.
b) Mempunyai 192 karakter tersimpan
c) Terdapat karakter generator terprogram.
d) Dapat dialamati dengan mode 4-bit dan 8-bit.
e) Dilengkapi dengan back light. 


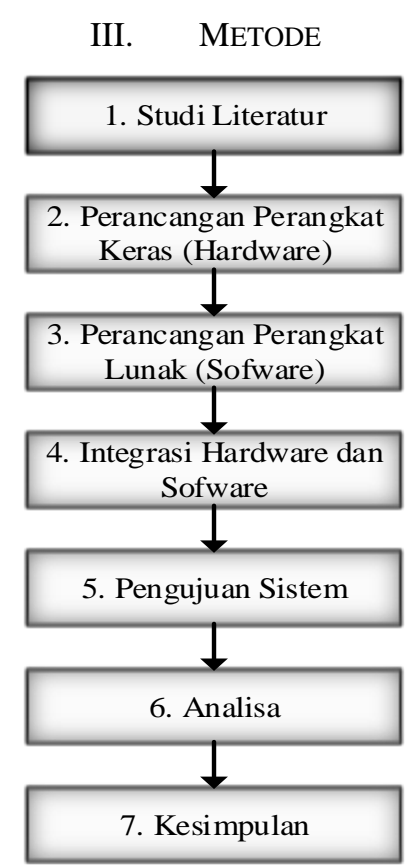

Gambar 1. Kerangka Pennelitian

Dapat di lihst pada gambar 1. kerangka penelitianini dimulai dari beberapa tahapan berikut ini :

1. Studi Literatur

Pada tahap ini penulis mempelajari serta membaca arsip jurnal yang berkaitan dengan penelitian. Studi literatur dilakukan dengan cara menelusuri sumber-sumber sebelumnya. Baik berupa sumber buku, jurnal nasiomal ataupun sumber dari internet.

2. Perancangan Perangkat Keras

Pada tahapan ini penulis akan membangun rancangan yang sesuia dengan simulasi. Semua momponen yang dibutuhkan pada tahpan ini ialah Arduino Uno ATmeg328, Relay, sesnor dht11, lampu, modul gsm sim 8001, lcd dan kipas.

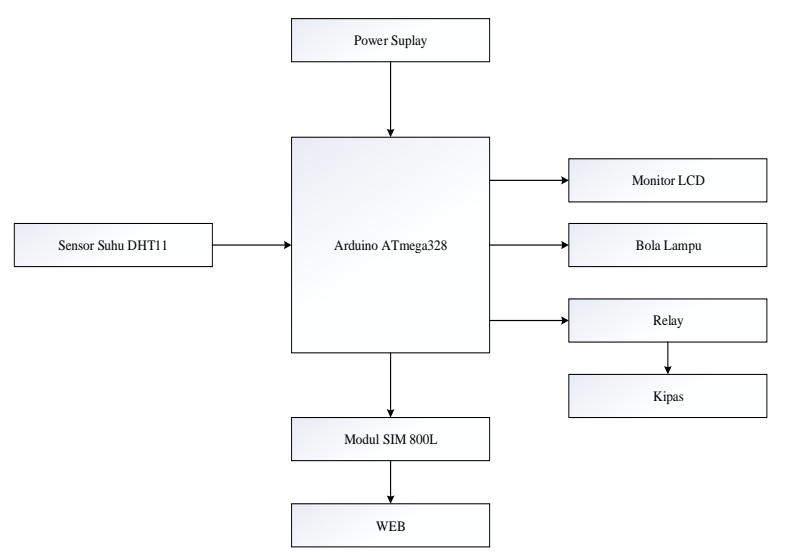

Gambar 2. Blok Diagram Perangkat Keras

3. Perancangan Perangkat Lunak

Pada tahap ini, penulis akan membangun rancangan perangkat lunak (software) yang pada tahap ini merupakan alur sistem dari keseluruhan penelitian ini.

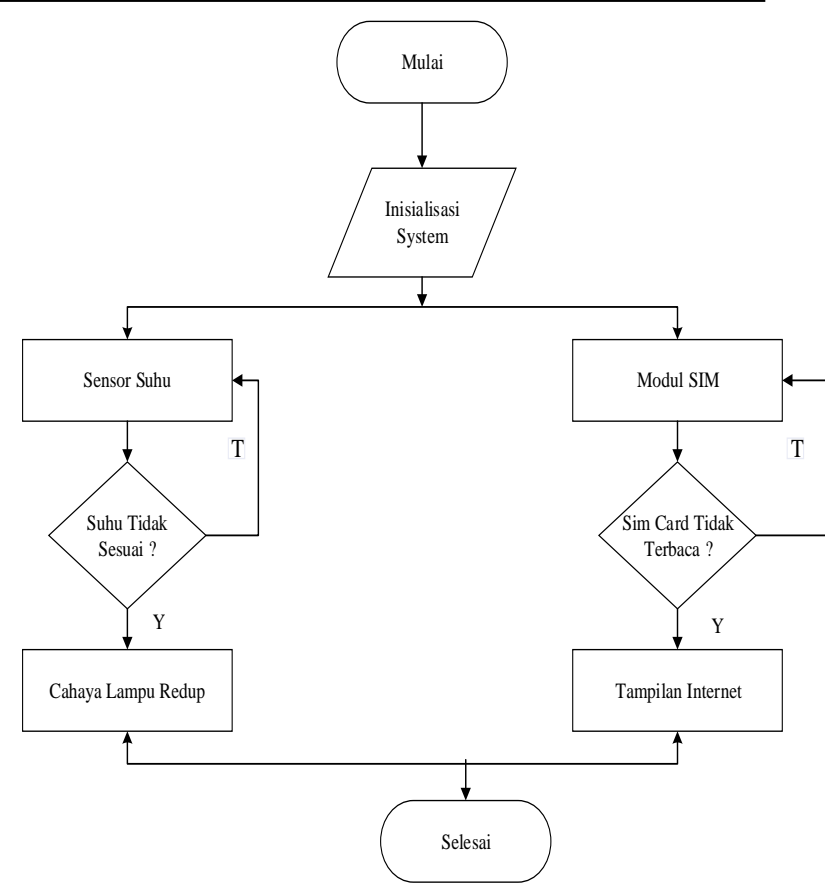

Gambar 3. Diagram Alir

4. Integrasi Hardware \& Software

Pada tahap ini,penulis menghubungkan kedua perangkat agar menjadi sebuah sitem yang dapat bekerja secara kesluruhan dan saling berkesinambungan.

5. Pegujian Sistem Alat

Pada tahap ini, penulis menguji alat yang telah terintgrasi dan diuji fungsi dari alat yang sudah selesai dibangun. Parameter yang diuji ialah sensor suhu dan kelembaban.

6. Analisa

Pada tahap ini, penulis mengkaji hasil dari rancangan alat yang sudah di uji dengan baik.

\section{Kesimpulan}

Pada tahap ini, penulis merangkum dari penelitian secara keseluruhan agar mendapatkan point-point penting.

\section{HASIL DAN PEMBAHASAN}

\subsection{Hasil Perancangan Alat}

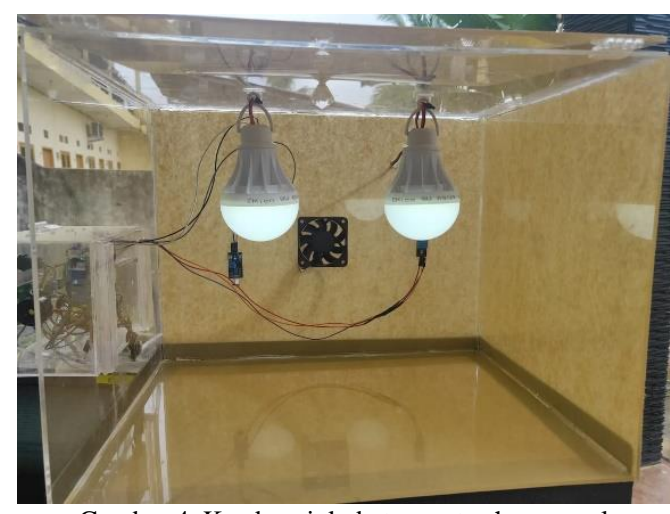

Gambar 4. Keadaan inkubator saat suhu normal 

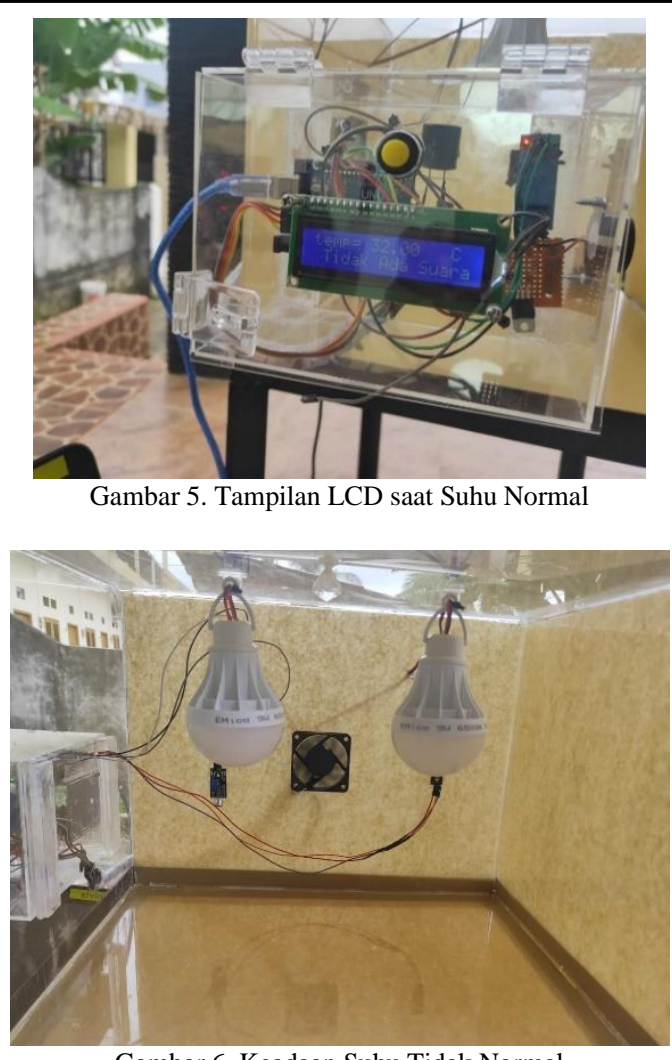

Gambar 6. Keadaan Suhu Tidak Normal

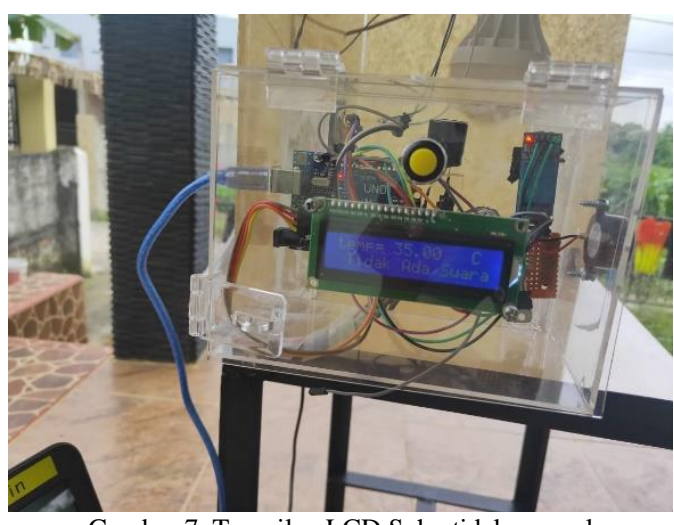

Gambar 7. Tampilan LCD Suhu tidak normal

Pada Gambar 4, 5, 6, dan 7 merupakan hasil dari pengujian alat. Yang dimulai pada saat keadaan suhu normal yang ditunjukan pada gambar 4 dan 5 sehingga lampu tetap menyala sehingga temperature pada tabung dalam kondisi stabil. Pada gambar 6 dan 7 menunjukan bahwa suhu berada di atas normal yang ditunjukan dengan lampu mati dan kipas menyala, kipas di fungsikan untuk membantu dalam penyetabilan suhu agar kembali stabil.

\subsection{Hasil Pengujian Alat}

Tabel 1. Hasil Pengujian Sensor

\begin{tabular}{|c|c|c|c|}
\hline No & $\begin{array}{c}\text { Range } \\
\text { Suhu }\end{array}$ & $\begin{array}{l}\text { Keadaan } \\
\text { Lampu }\end{array}$ & Kipas \\
\hline 1. & $32^{0} \mathrm{C}$ & Menyala & Mati \\
\hline 2. & $31^{0} \mathrm{C}$ & Menyala & Mati \\
\hline 3. & $31^{0} \mathrm{C}$ & Menyala & Mati \\
\hline 4. & $31^{0} \mathrm{C}$ & Menyala & Mati \\
\hline
\end{tabular}

\begin{tabular}{|c|c|c|c|}
\hline 5. & $30^{0} \mathrm{C}$ & Menyala & Mati \\
\hline 6. & $30^{\circ} \mathrm{C}$ & Menyala & Mati \\
\hline 7. & $30^{\circ} \mathrm{C}$ & Menyala & Mati \\
\hline 8. & $30^{0} \mathrm{C}$ & Menyala & Mati \\
\hline 9. & $31^{0} \mathrm{C}$ & Menyala & Mati \\
\hline 10. & $31^{0} \mathrm{C}$ & Menyala & Mati \\
\hline
\end{tabular}

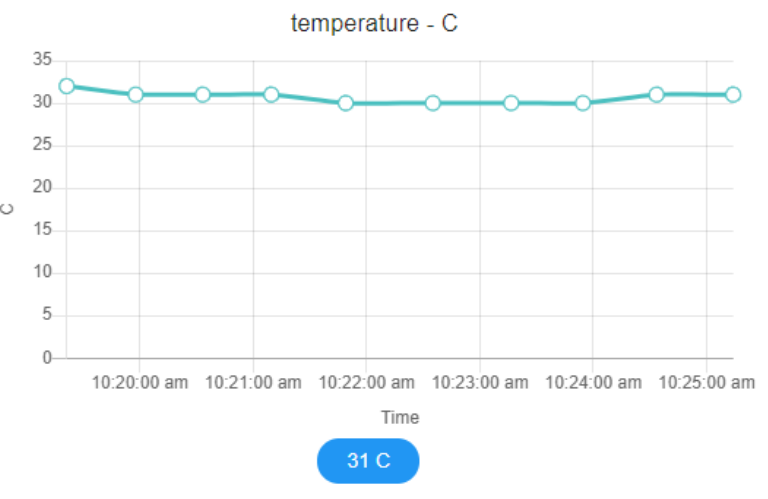

Gambar 8. Grafik Suhu Normal

Dari Tabel 1 dan gambar 8 di atas menunjukan jika suhu masih dalam kedaan normal,dapat di lighat pada range suhu yang setiap detiknya memiliki penurunan atau tetap stabil dengan suhu tetap aman untuk bayi yang berada di dalam tabung inkubator.

Tabel 2. Hasil Pengujian Sensor

\begin{tabular}{|c|c|c:c|}
\hline No & $\begin{array}{c}\text { Range } \\
\text { Suhu }\end{array}$ & Keadaan Lampu & Kipas \\
\hline 1. & $29^{0} \mathrm{C}$ & Menyala & Mati \\
\hline 2. & $30^{0} \mathrm{C}$ & Menyala & Mati \\
\hline 3. & $29^{0} \mathrm{C}$ & Menyala & Mati \\
\hline 4. & $30^{0} \mathrm{C}$ & Menyala & Mati \\
\hline 5. & $33^{0} \mathrm{C}$ & Mati & Menyala \\
\hline 6. & $35^{0} \mathrm{C}$ & Mati & Menyala \\
\hline 7. & $33^{0} \mathrm{C}$ & Mati & Menyala \\
\hline 8. & $32^{0} \mathrm{C}$ & Mati & Menyala \\
\hline 9. & $31^{0} \mathrm{C}$ & Menyala & Mati \\
\hline 10. & $31^{0} \mathrm{C}$ & Menyala & Mati \\
\hline
\end{tabular}

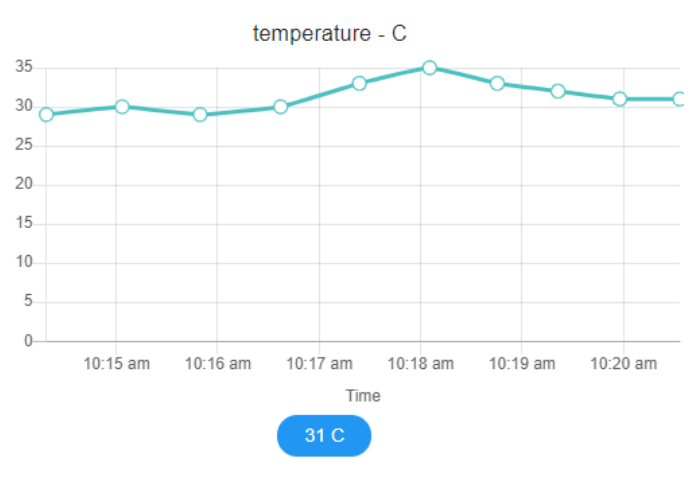

Gambar 9. Grafik Kenaikan Suhu 
Dari tabel 2 dan gambar 9 menunjukan jika keadaan suhu memiliki kenaikan, akan tetapi range suhu yang paling tinggi ialah $35^{\circ} \mathrm{C}$ sehingga suhu pada inkubator sangat panas, kipas menyala secara otomatis untuk membantu menurunkan suhu agar kembali dalam keadaan normal secara bertahap. Kipas akan mati jika suhu dalam tabung inkubator kembali normal dengan range sekitar $29^{\circ}$ $\mathrm{C}-32^{0} \mathrm{C}$ dan keadaan lampu menyala.

\section{KESIMPULAN}

Berdasarkan penelitian yang telah dilakukan serta pembahasan yang telah diuraikan, maka dapat di simpulkan jika monitoring temperature bayi dengan sistem wireless sensor network berbasis arduino uno ATmega328 ini sangat cocok jika digunakan pada instansi rumah sakit yang masih menggunakan pengawasan suhu pada inkubator secara manual sehingga pengawasan dapat dilakukan dengan jarak jauh tanpa harus turun langsung ke ruangan inkubator. Pada range suhu berada pada posisi $<32^{\circ} \mathrm{C}$ lampu akan tetap menyala sehingg suhu pada tabung inkubator tetap stabil dan kipas dalam keadaan mati, sedangkan suhu pada range $>32^{\circ} \mathrm{C}$ lampu akan mati secara otomatis dan kipas akan menyala untuk membantu mentstabilkan suhu pada tabung agar kembali normal

\section{REFERENSI}

[1] Junaidi, A. (2017). RANCANGAN MONITORING KELEMBABAN TEMPERATUR RUANG INKUBATOR BAYI MENGGUNAKAN VISUAL BASIC \& ATMEGA 16. 1(2).

[2] Nafie, Y. S., Tarigan, J., \& Louk, A. C. (2017). Rancang Bangun Sistem Kontrol Parameter Fisis Pada Inkubator Bayi Berbasis
Mikrokontroler Arduino Uno Dan Esp 8266. Jurnal Fisika Sains Dan Aplikasinya, 2(1), 37-43. http://ejurnal.undana.ac.id/FISA/article/view/541

[3] Irawan, H., Rivai, M., \& Budiman, F. (2017). Rancang Bangun Wireless Sensor Network Pada Pendeteksi Dini Potensi Kebakaran Lahan Gambut Menggunakan Banana Pi IoT. Jurnal Teknik ITS, 6(2). https://doi.org/10.12962/j23373539.v6i2.26016

[4] Wijaya, R. A., Lestari, S. W. L. W., \& Mardiono, M. (2019). Rancang Bangun Alat Monitoring Suhu dan Kelembaban Pada Alat Baby Incubator Berbasis Internet Of Things. Jurnal Teknologi, 6(1), 52. https://doi.org/10.31479/jtek.v6i1.5

[5] Syaifudin, M., Rofii, F., \& Qustoniah, A. (2019). Rancang Bangun Sistem Monitoring Tempat Sampah Rumah Tangga Dan Penerangan Jalan Berbasis Wireles Sensor Network (Wsn). Transmisi, 20(4), 158. https://doi.org/10.14710/transmisi.20.4.158-166

[6] Dewi, R. (2018). Rancang Bangun Sistem Pengendalian Listrik Ruangan Dengan Menggunakan Atmega 328 Dan Sms Gateway Sebagai Media Informasi. Jurnal Sistem Informasi, Teknologi Informatika Dan Komputer, 7(2), 10.

[7] Wisjhnuadji, T. W., Andrianto, S. B., Komputer, S., Informasi, F. T., Luhur, U. B., Utara, P., \& Lama, K. (2017). BIT VOL 14 No . 2 September 2017 ISSN: 1693-9166 INKUBATOR BAYI OTOMATIS DENGAN KONTROL SUHU DAN KELEMBABAN UDARA MELALUI WEB DAN SMS ISSN : 1693-9166. 14(2), 3843.

[8] Sahat Martua Parulian, P., \& Achmad Imam, A. (2019). Rancang Bangun Amf-Ats Berbasis Sim800L Dengan Fungsi Monitoring Status Switching Pada Genset. Jurnal Teknik Elektro. https://jurnalmahasiswa.unesa.ac.id/index.php/JTE/article/download /25787/23632

[9] Bintang, A. (2017). Rancang Bangun Alat Ukur Kelembaban Udara dan Suhu pada Laboratorium Volume dengan menggunakan Sensor DHT-11 Berbasis Arduino Uno. d.

[10] Adewasti, Rosila. F, Sholihin, Eka. Susanti, Emilia.H. (2018). Xbeepro module application in tonorganize and monitoring earthguaco disarter location with the robot control system. ICOIACT 2018. Jogjakarta, indonesia. Elektronic ISBN: 978-1-5386-0954-5. 